\title{
Dietary Calcium Intake, Vitamin D Status, and Bone Health in Postmenopausal Women in Rural Pakistan
}

\author{
Nicola M. Lowe', Basma Ellahi², Qudsia Bano³, Sonia Ali Bangash³, \\ Soma R. Mitra', and Mukhtiar Zaman ${ }^{4}$ \\ 'International Institute of Nutritional Sciences and Applied Food Safety Studies, University of Central Lancashire, Preston, \\ United Kingdom, ${ }^{2}$ Department of Clinical Sciences, University of Chester, Chester, United Kingdom, ${ }^{3}$ Emergency Satellite \\ Hospital, Nahaqi, Khyber Pakhtunkhawa, Pakistan, and ${ }^{4}$ Khyber Teaching Hospital, Peshawar, Khyber Pakhtunkhawa, Pakistan
}

\section{ABSTRACT}

The high prevalence of osteoporosis in Pakistan is of public-health concern. However, there is a paucity of information regarding nutrition and bone density in rural communities. The purpose of this study was to evaluate the dietary and lifestyle factors that impact bone health in Nahaqi. Data were collected from 140 postmenopausal women using an interviewer-administered 24-hour dietary recall questionnaire. Bone mineral density was estimated using the quantitative ultrasound index (QUI). Serum 25(OH)D was measured in fasting blood samples. The QUI scores revealed that $42 \%$ and $29 \%$ of the women had T-scores, indicative of osteopaenia and osteoporosis respectively. The mean calcium intake was $346 \mathrm{mg} / \mathrm{d}$, which is less than $50 \%$ of the recommended daily intake. The QUI correlated with $25(\mathrm{OH}) \mathrm{D}$ after controlling for age $\left(\mathrm{p}=0.021, \mathrm{r}=0.41, \mathrm{r}^{2}=0.168\right)$. Vitamin $\mathrm{D}$ deficiency and low intake of dietary calcium are two key factors contributing to poor bone health in this population.

Key words: Bone health; Bone mineral density; Calcium; Osteoporosis; Quantitative ultrasound index; 25(OH)D; Vitamin D deficiency; Pakistan

\section{INTRODUCTION}

The prevalence of osteoporosis in Pakistan is high, with $97 \%$ of women aged $75-84$ years and $55 \%$ of women aged 45-54 years predisposed to osteoporosis (1). Such women can present with back pain, loss of height, and stooped posture before fracture occurs. The symptoms are primarily a consequence of reduced bone mineral density and microarchitecture that occurs postmenopause due to a fall in oestrogen levels. Developing peak bone mass is influenced by genetics and multiple lifestyle characteristics (2). Some risk factors for osteoporosis, such as age, maternal history of hip fracture, current smoking, alcohol intake, low body-weight, and falls, are partially independent of bone mineral

Correspondence and reprint requests should be addressed to:

Dr. Nicola M. Lowe

Centre for Applied Sport and Exercise Sciences

School of Psychology

University of Central Lancashire

Preston, PR1 2HE

United Kingdom

Email: nmlowe@uclan.ac.uk density (3), and assessment of clinical risk factors is used as a selection method for referral for dual energy $x$-ray absorptiometry (DEXA). DEXA remains the 'gold standard' diagnostic tool for osteoporosis but high cost and low availability restrict its use in primary care in Pakistan. Quantitative ultrasound measurements of the calcaneal bone are also recognized as a potential indicator of the risk of fracture (4). Studies have demonstrated a high correlation between the ultrasound measurements and the bone mineral density at the calcaneus and suggest that for every 1 standard deviation (SD) decrease in broadband ultrasound attenuation (BUA), there is a 2.3-fold increase in the risk of hip fracture $(5,6)$.

Important modifiable factors involved in the optimization of bone mineral density include adequate dietary calcium intake and vitamin D status, and lifestyle factors, including activity levels, parity, and age of menarche and menopause. Calciumbalance studies have concluded that low dietary calcium and/or low absorption of calcium may be a major risk factor for the development of osteoporosis $(7,8)$. However, studies using bone densitometry methods to investigate the role of calcium in the 
development of osteoporosis have yielded conflicting results $(9,10)$. Vitamin D plays a key role in calcium absorption and homeostasis, and there is increasing evidence supporting the role of vitamin D supplementation in the prevention of falls and fractures in elderly postmenopausal women (1113). Several studies in Europe have demonstrated that poor vitamin D status is a particular problem in European South Asian immigrant populations. It has been suggested that South Asian diets, coupled with reduced exposure to sunlight, may compromise calcium and vitamin D status $(14,15)$.

In a survey of 608 women aged 40 years or older attending two teaching hospitals in Peshawar, based on calcaneus BUA measurements, $12 \%$ of women were osteoporotic, and $35.6 \%$ were osteopaenic (16). The number of women with BUA scores, indicative of osteoporosis, increased with age; however, this study did not investigate diet, vitamin D, or lifestyle factors.

There is a paucity of detailed data regarding diet, vitamin D status, and bone health in rural populations in Pakistan, particularly from conservative Muslim regions where the wearing of a full burqa is a common practice and may impact on exposure to sunlight and, thus, vitamin D status.

The purpose of this study was to undertake an indepth investigation of bone health using ultrasound and the dietary and lifestyle factors that influence the achievement and maintenance of optimal bone mineral density in postmenopausal women living in a rural population in Nahaqi, near Peshawar in Khyber Pakhtunkhawa (formerly North West Frontier Province), Pakistan.

\section{MATERIALS AND METHODS}

\section{Study participants}

The study participants were women aged 40-65 years and at least one year postmenopausal. They were identified from the Nahaqi Research Database Project. The women were all resident in union councils-Khazana and Nahaqi-in close proximity to the Emergency Satellite Hospital. These communities are serviced by a team of Lady Health Workers (LHWs), each of whom is responsible for a cluster which is a defined number of households with population of no more than 1,000 individuals in a defined geographical area. Ten women from 14 LHW clusters were invited to participate in the study. The exclusion criteria included use of steroids, calcium and/or vitamin D supplementation, hormone-replacement therapy, renal diseases, diuretic use, and gastrointestinal disorders. All the selected participants fulfilled the criteria, and none was excluded.

\section{Analysis of diet and lifestyle}

The participants were invited to attend the Emergency Satellite Hospital in groups of 10 along with their LHWs. Briefing was given as a group, and the consent and criteria were verified. At the start of the study, each participant completed a health and lifestyle questionnaire that included questions regarding factors known to influence bone health. These included age of menopause and menarche, number of pregnancies, number of children, history of personal fracture and of siblings, smoking, drug-use, occupation, and household income. In addition, food intake was recorded using an interviewer-administered 24-hour recall questionnaire. The questionnaire was administered through faceto-face interview individually, and the researcher recorded the responses. Ranges of cooking utensils (cups, spoons, plates) were used for estimating the portion size. The intake of nutrients was calculated using food tables (17) and an electronic database (Nutrisurvey for windows. Copyright@2007. Dr. Juergen Erhardt Sameo-Tropmed Rcc, Indonesia. www.nutrisurvey.de). This food intake questionnaire was conducted at each subsequent visit to the Emergency Satellite Hospital for the purposes of this study, which occurred on two or three separate occasions in each season.

Physical activity levels: Physical activity was also documented at the same time as the diet recall questionnaire was administered. This was done through face-to-face interview individually. The researcher recorded the responses. Each participant was asked to recall their activities for the whole 24 hours, starting from the early morning prayer (waking up) to the next morning prayer. The total amount of physical activity was quantified by multiplying time spent on activities with respective metabolic equivalent (MET) values (18). The total MET-hours (per day) was divided by 24 (total hours in a day) to calculate the physical activity level (PAL) for each participant.

\section{Bone ultrasound and anthropometry}

At the start of the study, height and weight of the participant were recorded and were used for calculating body mass index (BMI). Bone health was evaluated and estimated using BUA and speed of sound measurements of the calcaneus, combined to give the quantitative ultrasound index (QUI) (SAHARA; Hologic Inc., Bedford, MA, USA). The trained technicians performed the test. The results are reported in T-score which is a measure of the bone density of the participants compared to a normal healthy young adult of the same sex. According to the manufacturer of the instrument, a 
T-score above -1 indicates that the bone density is normal, a score between -1 and -2.4 is indicative of osteopaenia, and a score of -2.5 and below is indicative of osteoporosis.

\section{Blood 25(OH)D and parathyroid hormone}

Fasting blood samples were taken from a representative subgroup of the study women. The subgroup comprised 31 women randomly selected from each of the three categories based on their QUI scores: 13 women with a score above $-1,13$ women with a score between -1 and -2.5 , and 11 women with a score below -2.5 .

Parathyroid hormone (PTH) levels were measured using the chemiluminescent technique (immulite-100 Siemens) and 25(OH)D using the electrochemiluminescent technique (E-170 Roche) at the Clinical Laboratories of the Aga Khan University Hospital, Karachi. For quality assurance, PTH and 25(OH)D internal control samples, provided by the respective assay manufacturers, were run with every batch of samples from patients. All control values fell within \pm 2 standard deviation of the reference. In addition, an external control for PTH assay was run by the laboratory on a bi-weekly basis.

\section{Analysis of data}

Statistical tests were performed using the SPSS software for Windows (version 17.0). Repeated measures ANOVA was used for determining the effect of season on the nutrient intake and physical activity level. Pearson's correlation test was used for correlation analysis. A value of $\mathrm{p} \leq 0.05$ was considered significant.

\section{Ethical approval}

The women gave verbal consent (100\% of them were uneducated) and agreed to come for faceto-face interview to the Emergency Satellite Hospital in Nahaqi on at least eight occasions in the 12-month study period. The Faculty of Science Ethics Committee of the University of Central Lancashire approved the study. The study was conducted in accordance with the ethical standards of the University, and the procedures followed were in accordance with the Helsinki Declaration.

\section{RESULTS}

\section{Health and lifestyle characteristics}

Factors that may influence bone health are presented in Table 1 . The average BMI was in the overweight range at $27.9 \mathrm{~kg} / \mathrm{m}^{2}$. However, $5 \%$ of the women were underweight (BMI $\leq 19 \mathrm{~kg} / \mathrm{m}^{2}$ ), 31\% were in the healthy range (BMI $\left.>19 \leq 25 \mathrm{~kg} / \mathrm{m}^{2}\right)$,

\begin{tabular}{|c|c|c|}
\hline Characteristics & Mean \pm SD & Range \\
\hline Age (years) & $52 \pm 6$ & $41-67$ \\
\hline Weight (kg) & $63 \pm 13$ & $35-97$ \\
\hline Height (m) & $1.52 \pm 0.13$ & $1.20-1.76$ \\
\hline BMI $\left(\mathrm{kg} / \mathrm{m}^{2}\right)$ & $27.3 \pm 5.7$ & $16.5-48.0$ \\
\hline Parity & $5 \pm 3$ & $0-13$ \\
\hline $\begin{array}{l}\text { Age (years) of } \\
\text { menarche }\end{array}$ & $13 \pm 1$ & $12-14$ \\
\hline $\begin{array}{l}\text { Age (years) } \\
\text { of onset of } \\
\text { menopause }\end{array}$ & $46 \pm 2$ & $40-49$ \\
\hline $\begin{array}{l}\text { No. of } \\
\text { pregnancies }\end{array}$ & $8 \pm 4$ & $0-20$ \\
\hline
\end{tabular}

$38.1 \%$ were overweight (BMI $<25 \leq 30 \mathrm{~kg} / \mathrm{m}^{2}$ ), and $25.9 \%$ were in the obese category $\left(\mathrm{BMI}>30 \mathrm{~kg} / \mathrm{m}^{2}\right)$. None of the women reported ever having used tobacco (cigarette, snuff, or huqqa) or opium. Of the 140 women, 10 reported long-standing illness, including diabetes $(n=7)$ and hypertension $(n=2)$, and one was blind. None reported having sustained a bone fracture herself, nor having a parent or sibling who had sustained a bone fracture. Most women were married $(n=92)$, or widowed $(n=46)$, with one single and one divorced. Their occupations reported included: housewife $(n=29)$, domestic helper $(\mathrm{n}=44)$, other (including midwife, basket maker, hawker, and tailor) $(n=50)$, and retired $(n=17)$. The number of women reporting an average monthly household income in the following ranges were: Rs $>30-<300(n=30)$, Rs $>300-<600(n=72)$, Rs $>600-$ $<900(\mathrm{n}=20)$, and Rs $>900(\mathrm{n}=18)$ (US $\$ 1=$ Rs 85.64). None reported having sustained a fracture herself, nor having a sibling who had sustained a fracture. None had undergone a hysterectomy, and none reported ever having used tobacco or recreational drugs.

\section{Analysis of diet}

The range of foods consumed by the participants was limited. The most commonly-consumed foods are shown in Table 2. Analysis of the nutrient content of the diet and physical activity by season is shown in Table 3 . The total energy intake increased significantly with each season from summer to autumn and winter, with a concurrent fall in the percentage of calories coming from carbohydrate, and an increase in percentage of calories from protein during the winter months. This was associated with an increase in calcium and zinc intakes from summer to autumn and autumn to winter. The mean calcium intake was significantly lower than the World Health Organization's dietary recommended intake of $1,300 \mathrm{mg} / \mathrm{day}$, and the more conservative UK reference nutrient intake value for 


\begin{tabular}{|ll|}
\hline \multicolumn{2}{|l|}{ Table 2. Commonly-used foods by participants } \\
\hline Food-group & Commonly-used foods \\
\hline $\begin{array}{l}\text { Milk and milk } \\
\text { products }\end{array}$ & Milk and curd \\
Cereals and & Wheat, rice, lentil, cow \\
pulses & pea, and kidney bean \\
Carbohydrates & Sugar (sucrose) \\
Lipids & Fats (ghee) \\
Meat-group & Meat and poultry \\
Vegetables & Potato, cabbage, green \\
& pea, lady finger, guard, \\
& bitter guard, brinjal, \\
Fruits & onion, and tomato \\
& Use of fruits was very rare \\
\hline
\end{tabular}

2 respectively. When removing the effect of age, serum $25(\mathrm{OH}) \mathrm{D}_{3}$ still accounted for $16.8 \%$ of the variation in the QUI $\left(\mathrm{p}=0.021, \mathrm{r}=0.41, \mathrm{r}^{2}=0.168\right)$. There were no significant correlations between the QUI and the BMI, PTH, calcium intake, number of children, age of menarche or menopause, protein intake, or physical activity levels.

\section{DISCUSSION}

The purpose of the study was to explore the prevalence of osteoporosis and osteopenia and the dietary and lifestyle factors that may affect bone health in a relatively-small sample of postmenopausal women living in a region near Peshawar in Khyber Pakhtunkhawa. This rural region is served

\begin{tabular}{|c|c|c|c|c|c|c|}
\hline \multirow[t]{2}{*}{ Outcome measure } & \multicolumn{2}{|c|}{$\begin{array}{c}\text { Summer } \\
\text { (June-August) }\end{array}$} & \multicolumn{2}{|c|}{$\begin{array}{c}\text { Autumn } \\
\text { (September-November) }\end{array}$} & \multicolumn{2}{|c|}{$\begin{array}{c}\text { Winter } \\
\text { (December-February) }\end{array}$} \\
\hline & Mean & SD & Mean & SD & Mean & SD \\
\hline No. & \multicolumn{2}{|c|}{140} & \multicolumn{2}{|c|}{109} & \multicolumn{2}{|c|}{100} \\
\hline Physical activity level & 1.26 & 0.12 & 1.28 & 0.12 & 1.28 & 0.12 \\
\hline Energy intake (kcal) & $1,646.6^{\mathrm{a}}$ & 341 & $1,789.2^{\mathrm{b}}$ & 250.4 & $1,909.5^{c}$ & 203.4 \\
\hline \multicolumn{7}{|l|}{$\%$ of energy from } \\
\hline Carbohydrate & $61.9^{\mathrm{a}}$ & 6.1 & $59.9^{\mathrm{b}}$ & 5.2 & $57.3^{\mathrm{c}}$ & 4.4 \\
\hline Protein & $11.4^{\mathrm{a}}$ & 1.3 & $11.4^{\mathrm{a}}$ & 1.4 & $14.0^{\mathrm{c}}$ & 2.4 \\
\hline Fat & 26.2 & 5.7 & 27.3 & 4.4 & 27.1 & 2.6 \\
\hline Calcium (mg) & $316.9^{a}$ & 99.4 & $354.7^{b}$ & 128.4 & $367.1^{c}$ & 60.0 \\
\hline Zinc (mg) & $10.1^{\mathrm{a}}$ & 2.1 & $11.9^{\mathrm{b}}$ & 1.7 & $13.9^{\mathrm{c}}$ & 4.4 \\
\hline
\end{tabular}

Values with different superscripts are significantly different from each other according to the season. $\mathrm{p}<0.05$; Repeated measures ANOVA; ANOVA=Analysis of variance; $\mathrm{SD}=$ Standard deviation

calcium of $700 \mathrm{mg}$ per day $(\mathrm{p}<0.001)$. PALs for this group of women were consistent with sedentary, inactive lifestyles (19). There were no significant seasonal changes in PAL. Quantitative ultrasound measurements,
$25(\mathrm{OH}) \mathrm{D}$, and parathyroid hormone

Quantitative ultrasound measurements were made in 107 of the 140 women recruited onto the study. The T-scores revealed that $32(30 \%)$ of the participants had T-scores within the normal range, 46 (43\%) were in the osteopaenic range, and 29 (27 $\%$ had T-scores, indicative of osteoporosis. The median value within each of these three categories are shown in Table 4 , along with serum $25(\mathrm{OH}) \mathrm{D}$, and PTH levels were measured in a sample of the participants from each T-score category.

\section{Analysis of correlation}

There was a significant correlation between the QUI T-score and age $\left(\mathrm{p}=0.001, \mathrm{r}=0.303, \mathrm{r}^{2}=0.091\right)$ and between the QUI score and serum $25(\mathrm{OH}) \mathrm{D}(\mathrm{p}=0.031$, $\mathrm{r}=0.387, \mathrm{r}^{2}=0.149$ ). These are shown in Figure 1 and by the Emergency Satellite Hospital in Nahaqi, and the population here is uneducated and of lowsocioeconomic status. Over $70 \%$ of the participants reported household incomes of less than Rs 600 per month. The poverty-line is considered to be Rs 723 per month. It was hypothesized that poor diet (primarily a result of poverty) and suboptimal vitamin D status, due to the wearing of a full burqa, thus, limiting exposure to sunlight, would result in a high incidence of osteoporosis and osteopaenia in this population. The results of the study indicate that over two-thirds of the study women had QUI scores indicative of osteoporosis or osteopaenia. This concurs with results of previous studies in the Peshawar survey of a larger group of over 600 women aged over 40 years, which revealed that almost $50 \%$ had decreased bone mineral density (T-score $<-1)(16)$.

One of the strengths of the present study was that a detailed dietary analysis was undertaken over a 12-month period, enabling the dietary factors that may contribute to bone health to be evaluated. In 


\begin{tabular}{|c|c|c|c|c|c|c|}
\hline \multirow{2}{*}{ Category } & \multicolumn{2}{|c|}{ T-score } & \multicolumn{2}{|c|}{$25(\mathrm{OH}) \mathrm{D}(\mathrm{ng} / \mathrm{mL})$} & \multicolumn{2}{|l|}{ PTH (pg/mL) } \\
\hline & Median & No. & Median (range) & No. & Median (range) & No. \\
\hline T-score above -1 & 0.00 & 32 & $23.95(18.10-29.44)$ & 13 & 89.7 (43.2-99.9) & 13 \\
\hline $\begin{array}{l}\text { T-score between } \\
-1 \text { and } 2.5\end{array}$ & -1.65 & 46 & $17.91(14.26-22.42)$ & 13 & $73.8(23.5-169)$ & 13 \\
\hline T-score below -2.5 & -2.8 & 27 & $18.71(14.0-25.76)$ & 11 & $84.2(21.5-122)$ & 11 \\
\hline
\end{tabular}

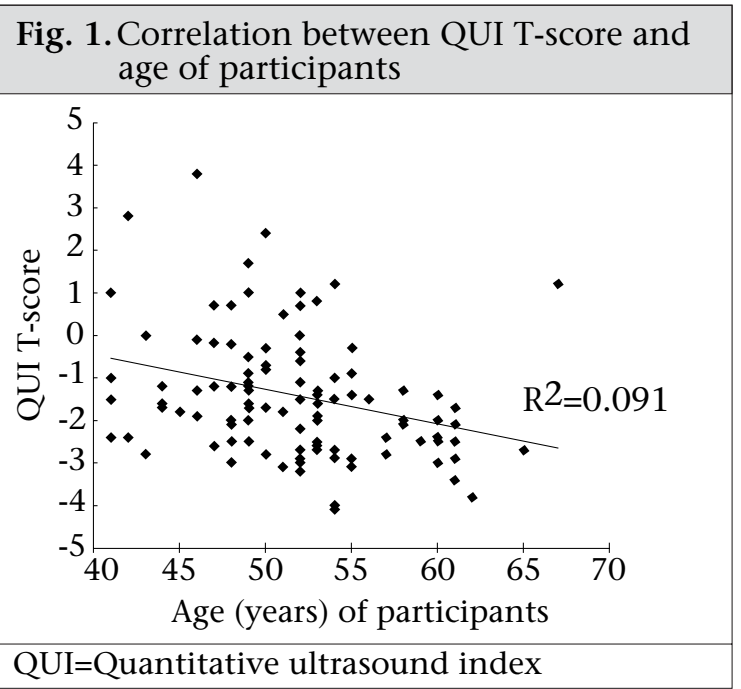

general, the macronutrient content of the diet met energy requirements and were broadly in line with the dietary recommendations (20), with $60 \%$ energy from carbohydrate, $12 \%$ from protein, and $27 \%$ from fat. An adequate calcium intake is essential for bone mineralization, and zinc forms an important structural component of bone. The zinc intake met the World Health Organization's (WHO's) recommendation of $6.5 \mathrm{mg}$ per day. However, the results of this study revealed that dietary calcium intakes in these women fell far below the WHO's recommendation of 1,300 mg per day. There were some seasonal fluctuations in total energy intake, with more calories being consumed in the winter months. Analysis of the 24-hour recall data indicated that this was reported to be primarily due to an increase in the consumption of hot milky tea during the cooler months, leading to an increase in protein, calcium and zinc intakes. However, calcium intake remained significantly below the recommended amount.

In the present study, calcium intake did not correlate significantly with the QUI scores. A number of epidemiological studies have also failed to show an association between higher intakes of calcium and increased bone density or a decreased incidence of osteoporotic fracture $(21,22)$. However, it is likely that calcium intake during childhood and adolescence plays a significant role in ensuring the acquisition of optimal peak bone density within genetic limits (23).

Fasting blood samples taken from a sample of the participant pool were analyzed for $25(\mathrm{OH}) \mathrm{D}$ and PTH levels. It is widely accepted that concentrations of less than $20 \mathrm{ng} / \mathrm{mL}$ represent vitamin D deficiency (24). Only nine of the 37 women sampled in the study had $25(\mathrm{OH}) \mathrm{D}$ levels that were above this cut-off value, suggesting a high prevalence of $25(\mathrm{OH}) \mathrm{D}$ deficiency in this population. Very few foods naturally contain vitamin $\mathrm{D}$; hence, vitamin D requirements are met largely by exposure to sun. The practice of wearing a full burqa when outdoors in commonplace in the Nahaqi community which limits exposure to sunlight and is the most likely reason for the low vitamin D status. Vitamin D plays an important role in the absorption of calcium; therefore, the low vitamin D status in these women compounds the low dietary calcium intake.

The main limitation of this study is the relatively small sample-size, particularly of the blood analyses which was due to the high cost of these analyses. Despite this small sample, we have demonstrated

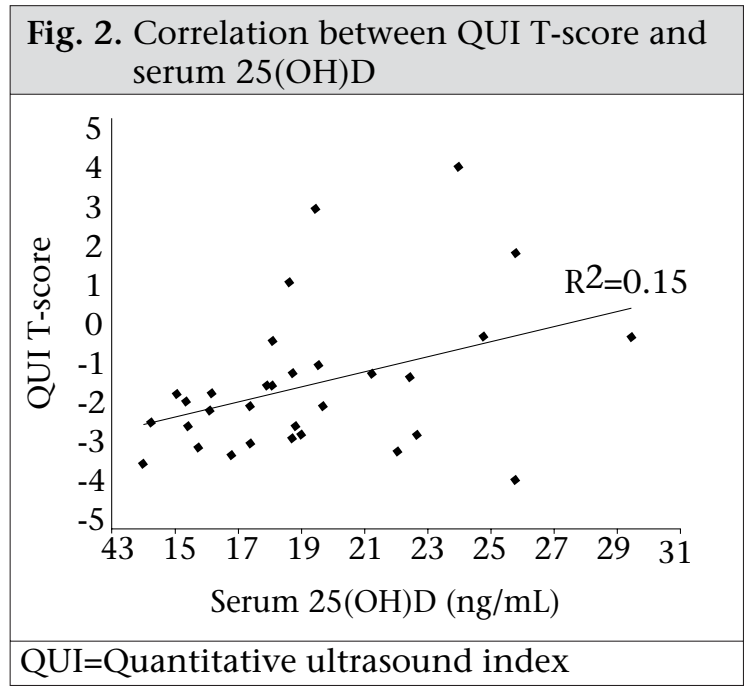


a highly-significant relationship between $25(\mathrm{OH}) \mathrm{D}$ and the QUI T-scores which warrants further investigation. We have also demonstrated a low dietary calcium intake by postmenopausal women in this community, which, coupled with low vitamin D status, will result in a very low rate of calcium absorption. This study highlights the importance of improving the calcium intake and vitamin D status of women living in this rural region of Khyber Pakhtunkhawa. Young women should, therefore, be particularly targeted through community nutrition and health-education programmes because the benefits of optimal nutrition can have the greatest impact on bone mineralization in late teens and early 20 s.

\section{ACKNOWLEDGEMENTS}

The authors gratefully acknowledge the support of the Abaseen Foundation (UK-registered Charity No. 1095882) which was instrumental in facilitating the study.

\section{REFERENCES}

1. Habiba U, Ahmad S, Hassan L. Predisposition to osteoporosis in postmenopausal women. J Coll Physicians Surg Pak 2002;12:297-301.

2. Kanis JA. Diagnosis of osteoporosis and assessment of fracture risk. Lancet 2002;359:1929-36.

3. Rubin LA, Hawker GA, Peltekova VD, Fielding LJ, Ridout R, Cole DE. Determinants of peak bone mass: clinical and genetic analyses in a young female Canadian cohort. J Bone Miner Res 1999;14:633-43.

4. Langton CM, Palmer SB, Porter RW. The measurement of broadband ultrasonic attenuation in cancellous bone. Engineering Med 1984;13:89-91.

5. Langton CM, Langton DK. Comparison of bone mineral density and quantitative ultrasound of the calcaneus: site-matched correlation and discrimination of axial BMD status. Br J Radiol 2000;73:31-5.

6. Pluijm SM, Graafmans WC, Bouter LM, Lips P. Ultrasound measurements for the prediction of osteoporotic fractures in elderly people. Osteoporosis Int 1999;9:550-6.

7. Heaney RP. Calcium intake requirement and bone mass in the elderly. J Lab Clin Med 1982;100:309-12.

8. Nordin BE, Need AG Morris HA Horowitz M. New approaches to the problems of osteoporosis. Clin Orthop Relat Res 1985;200:181-97.

9. Nilas L, Christiansen C, Rødbro P. Calcium supplementation and postmenopausal bone loss. $\mathrm{Br}$ Med J (Clin Res Ed) 1984;289:1103-6.

10. Matkovic V, Goel PK, Badenhop-Stevens NE, Landoll JD, Li B, Ilich JZ et al. Calcium supplementation and bone mineral density in females from childhood to young adulthood: a randomized controlled trial. Am J Clin Nutr 2005;81:175-88.

11. Mawer EB, Davies M. Vitamin D nutrition and bone disease in adults. Rev Endocrin Metabol Disord 2001; 2:153-64.

12. Mezquita-Raya P, Munoz-Torres M, Luna JD, Luna V, Lopez-Rodriguez F, Torres-Vela E et al. Relation between vitamin $\mathrm{D}$ insufficiency, bone density, and bone metabolism in healthy postmenopausal women. J Bone Mineral Res 2001;16:1408-15.

13. Pfeifer M, Begerow B, Minne HW, Schlotthauer T, Pospeschill M, Scholz M et al. Vitamin D status, trunk muscle strength, body sway, falls, and fractures among 237 postmenopausal women with osteoporosis. Experiment Clin Endocrin Diabet 2001;109:87-92.

14. Alfaham M, Woodhead S, Pask G, Davies D. Vitamin $\mathrm{D}$ deficiency: a concern in pregnant Asian women. $\mathrm{Br}$ J Nutr 1995;73:881-7.

15. Roy DK, Berry JL, Pye SR, Adams JE, Swarbrick CM, King Y et al. Vitamin D status and bone mass in UK South Asian women. Bone 2007;40:200-4.

16. Fahim F. The magnitude of low bone mineral [corrected] density in middle and old age women. J Pakistan Med Assoc 2005;55:500-2.

17. Gopalan C, Rama Sastri B, Balasubramanian S. Nutritive value of Indian foods. Hyderabad: National Institute of Nutrition, Indian Council of Medical Research, 1984. $34 \mathrm{p}$.

18. Ainsworth BE, Haskell WL, Leon AS, Jacobs DR Jr, Montoye HJ, Sallis JF et al. Compendium of physical activities: classification of energy costs of human physical activities. Med Sci Sports Exercise 1993;25:7180.

19. Food and Agriculture Organization. Human energy requirements: energy requirement of adults. Report of a Joint FAO/WHO/UNU Expert Consultation. Rome: Food and Agriculture Organization, 2004. 96 p.

20. Geissler C, Powers H. Human nutrition. $11^{\text {th }}$ ed. London: Elsevier Churchill Livingstone, 2005. 743 p.

21. Michaelsson K, Melhus H, Bellocco R, Wolk A. Dietary calcium and vitamin $\mathrm{D}$ intake in relation to osteoporotic fracture risk. Bone 2003;32:694-703.

22. Cumming RG, Nevitt MC, Cummings SR. Epidemiology of hip fractures. Epidemiol Rev 1997;19:244-57.

23. Sandler RB, Slemenda CW, LaPorte RE, Cauley JA, Schramm MM, Barresi ML et al. Postmenopausal bone density and milk consumption in childhood and adolescence. Am J Clin Nutr 1985;42:270-4.

24. Holick MF. Vitamin D deficiency. NEnglJ Med 2007; 357:266-81. 